\title{
Development the Food Safety and Sanitation Competences Indicators for Foodservice Employees
}

\author{
Wen-Hwa $\mathrm{Ko}^{1, *} \& \mathrm{I}-\mathrm{Fan} \mathrm{Hsiao}^{1}$ \\ ${ }^{1}$ Department of Restaurant, Hotel and Institutional Management, Fu-Jen University, No.510, Zhongzheng Rd., \\ Xinzhuang Dist., New Taipei City, Taiwan \\ *Corresponding author: Fu-Jen University, Department of Restaurant, Hotel and Institutional Management, No.510, \\ Zhongzheng Rd., Xinzhuang Dist., New Taipei City, Taiwan. Tel: 886-2-2905-3755. E-mail: \\ 073770@mail.fju.edu.tw
}

Received: February 20, 2017 Accepted: March 7, $2017 \quad$ Online Published: April 13, 2017

doi:10.5430/mos.v4n2p1

URL: https://doi.org/10.5430/mos.v4n2p1

\begin{abstract}
This study investigates the competence indicators for managers and kitchen staff of food safety and hygiene from a new perspective in order to establish competence indicators in further compliance with the existing requirements for food safety and hygiene. After a three-round Delphi method questionnaire, this study integrated the opinions of 20 experts and established the indicators of food safety and sanitation competences for foodservice employees. The results show that, for managers, management competence is more important than professional or core competences, while professional competence is the most important for kitchen staff. For managers, the most important core competence is professional ethics, the most important management competence is leadership; and the most important professional competence is knowledge of food safety and hygiene. In terms of kitchen staff, the most important core competence is professional ethics. Professional competence ensures hand washing and disinfection.
\end{abstract}

Keywords: foodservice employees; manager; kitchen staff; competence; food safety and sanitation

\section{Introduction}

Food and beverages have nutrients and must be safe, and any microorganisms or toxins generated due to improper handling or cross-contamination of food and beverages may lead to diarrhea, vomiting, fever, or even death. For instance, the botulinum toxin generated by improper sterilization of low-acid foods may be life-threatening. Food containing hazardous or toxic substances, put there intentionally or unintentionally, causes consumers concern, and can also cause irreparable loss. For example, the plasticizer event in 2011 revealed that some suppliers of food raw materials added illegal plasticizers. The poison starch event in 2012 revealed that unscrupulous food suppliers added maleic anhydride to traditional Taiwanese snacks, such as flat noodles, meatballs, and tapioca balls. Since some of these snacks are exported overseas, such as the tapioca balls, which are famous specialties of Taiwan, and this event greatly impacted the export of some foods and undermined Taiwan's reputation (Ko, 2015).

Due to the occurrences of food safety accidents and changes in the food industry, the food safety and hygiene laws and regulations of Taiwan have been amended accordingly. Taiwan's first food hygiene management act, issued on January 28, 1975, had 32 articles. After amendments, it was republished on February 9, 2000, and contained 40 articles, which strengthened the autonomous management system of owners, and included various regulations, such as compliance with good hygiene practices, food hygiene practices, and product liability insurance. However, due to the increasing severity, importance, and urgency of food safety issues in recent years, in 2012, Taiwan began to launch large-scale amendments to laws and regulations referring to the counterparts of various countries. On June 19, 2013, the President announced substantial amendments to the food hygiene management act, increased the articles from 40 to 60, and changed its name to the Food Safety and Hygiene Management Act. Several important chapters were added, such as, food safety risk management, food input management, and food inspection, review, control, and management. In November 2014, further amendments stipulated cross-department food safety management and added penalty regulations; after 12 small amendments on January 20, 2015, the act now contains a total of 10 
chapters and 67 articles. "Methods to Set up and Manage Owners of Food Industry with Special Occupation or Technology Certificates", as issued by the Ministry of Health and Welfare on February 24, 2014, clearly specified that the practitioners of prepared foods, catering bakeries, and bakery industries should attend at least eight hours of training annually on hygiene, which is held by competent authorities of various levels, or approved hygiene training authorities thereof, during their employment (MOHW/FDA, 2016a). This act aimed to provide further education to practitioners and enhance their core knowledge and core values through continuous educational courses. Due to the amendments to food safety and hygiene laws and regulations, it is necessary for practitioners of the catering industry to re-examine their food safety and hygiene competencies.

The foodservice industry is a labor- and technology-intensive industry. Human resources and talents often determine a $90 \%$ success of the industry (Sani \& Siow, 2014). Hygienic operation and management of the foodservice industry are closely related to the occurrences of food poisoning accidents (Tseng and Huang, 1995). Dining out has become a habit for most Taiwanese, thus, according to the statistics of the Food and Drug Administration in 2014, among the food poisoning events in Taiwan, schools were ranked the first in food poisoning cases, followed by places of food businesses, and offices. Regarding contaminated food or improper disposal of food, places of food businesses had the most frequent cases, followed by food manufactures (MOHW/FDA, 2016b). Thus, the foodservice industry shall immediately enhance the food safety and hygiene competencies of practitioners, provide consumers with safer dining environments, and safeguard consumers' food safety and interests.

Therefore, this study aims to rebuild the competence indicators of the foodservice industry regarding food safety and hygiene, perform comprehensive food safety and hygiene competence item amendments, and review from the perspective of industry, government, and schools in compliance with the latest food safety and hygiene laws and regulations. The purpose of this study is to establish the competence indicators of food safety and hygiene, which should be possessed by managers and kitchen staff.

\section{Literature Review}

\subsection{Food Hygiene and Safety}

Food hygiene starts from hygienic environments, and includes the hygiene conditions of foods, food additives, food containers and packaging, toxic and hazardous substances, pollutants, food poisoning, foodborne diseases, food manufacturing, processing, blending, storage, displaying, selling, transportation, dining, and places. Moreover, it is related to food labeling, advertising, and hygiene education. Hence, it is a comprehensive work (Rohr, Luddecke, Drusch, Muller, \& von Alvensleben, 2005). To ensure food safety and reliability, it is required to meet the sanitation conditions of food manufacturing, processing, blending, storage, displaying, selling, transportation, dining, and places, and reduce the pollution at various stages. Regarding consumers, they tend to link food safety with the pesticide sprayed on crops and the additives added during food production. Influenced by the current Taiwanese food safety issues, it becomes more important for managers of the catering industry to strengthen their control and management of food hygiene and safety. Food consumption has shifted its demands from "quantity" to "quality" (Brannon, York, Robert, Shanklin, \& Howells, 2009); nevertheless, many consumers attach less importance to food hygiene and safety than to price, taste, appearance, and other properties, thus, when they experience food problems, they tend to think that they just have bad luck, and do not call on the sellers to account; therefore, unscrupulous manufacturers and illegal foods still exist (Fatimah, Strohbehn, \& Arendt, 2014). Although food hygiene is the most basic and important part of food supply, it is often overlooked by consumers and food suppliers.

\section{Competencies of Employees in Foodservice Industry}

\subsection{Competence}

The term "competence" has a history of over 50 years in the field of human resources, which aims to help individuals work effectively and appropriately perform their roles, posts, and tasks at work (Rothwell \& Lindholm, 1999). Moreover, competence is based on a high level of practical procedures (Stone, 1997). Professional competencies refer to the abilities required by different workplaces, including individual potentials. The existing competencies are measured according to the execution conditions of a post. In terms of behavior, it refers to the abilities displayed and is related to work performance, which could be improved and strengthened through training and development (Mansfield, 1996).

Taiwan enterprises classify competence into three categories: Core competence (e.g. customer orientation and 
teamwork), management competence (e.g. level-specific competence), and professional competence (e.g. role competencies and functional competence) (Schoonover, 1998); wherein, functional competence is equivalent to professional competence, and typically includes professional knowledge, professional skills, and professional attitude. The competencies necessary for the successful work of an individual could be classified into three categories: Core competence or fundamental competence (e.g. the key abilities required for all the members of a workplace or organization), level-specific competence, and functional competence (Schoonover, 1998).

\subsection{Competence of Managers}

Leadership, interpersonal relationships, creativity, administration, and skills are the competencies required for the managers of restaurants and tourism industries (Kay \& Russette, 2000); wherein, culinary creativity has become an indispensable capability for a high-end chef in recent years (Horng and Lee, 2006; Ottenbacher and Harrington, 2007). Leadership and interpersonal relationship skills are necessary trends and important factors for successful management. Wei, $\mathrm{Lu}$, and $\mathrm{Li}$ (2008) assumed that, among the competencies of senior managers, training others, self-management, executive ability, analytical ability, and attitude were most important. In addition to management ability and leadership, Rodgers (2005) deemed that the major barrier to the development of modern tourist hotels was the demand for high-quality food by customers, which included the professional competencies of tourist hotel human resources. In other words, managers should identify the abilities of employees before assigning works to them.

\subsection{Competence of Kitchen Staff}

Ko and Li (2010) explored the professional competences of a chef, which covered five aspects: Basic knowledge of culinary arts, knowledge related to cooking skills, fundamental ability of cooking, peripheral ability of culinary arts, and attitude. The research results of Ko and Hsiao (2008) implied that a chef should have 26 professional competencies; wherein, 5 were knowledge indicators, namely, food sanitation and safety, ingredient characteristics, cuisine culture, concept of arranging dishes, and concept of environmental protection and health. There were 11 skill indicators, namely, kitchenwares, processing of ingredients, cooking, aesthetic creations, menu design, financial management, leadership, customer service, crisis management, computer, and language ability. There were 10 attitude indicators, including interest in the career of the chef, self-discipline, caution, modesty, proactive attitude, high pressure resistance, spirit of innovation, customer orientation, people orientation, and resource saving. Birdir and Pearson (2000) classified the competencies of chefs into two categories, namely, competencies for research focused chefs and competencies for management focused chefs. The United States Department of Labor, Employment and Training Administration (2006) considered that, the professional knowledge of chefs and foodservice managers should include raw materials, quality of production processes and cost control, administration and management, customer and personnel service, cooking skills and equipment planning, education and training, personnel and human resource management, and sales promotion and marketing.

\subsection{Common Competencies in Food Safety and Sanitation}

Regulations for food safety, sanitation training, and effective and safe food handling and practice are vital to control food-borne diseases (Dima, Victor, and Ewen, 2015). Current data shows that, most of the reasons for food poisoning events were due to improper handling of food by suppliers or customers (Howes, McEwen, Griffiths, \& Harris, 1996), and the hand pollution of the staff that provided the food and beverage, which is related to a lack of knowledge of employees (Greig, Todd, Bartleson, \& Michaels, 2007). While knowledge plays a significant role in improving behaviors and operations, it is not the only factor guiding proper food handling, as other factors are also necessary (Seaman \& Eves, 2008). Training and education, such as earning certificates, can enhance food handling and reduce food pollution during food preparation (Hislop and Shaw, 2009; Lynch, Elledge, Griffith \& Boatright, 2003). Employees with food safety and sanitation training experience are apparently more aware of their knowledge of safety, hygiene, and execution ability than those without training (McIntyre, Vallaster, Wilcott, Henderson, and Kosatsky, 2012).

\section{Research Method}

Based on the relevant regulations and issues of food safety and hygiene, as well as relevant literature, this study probes into the competencies that managers of the foodservice industry should possess, creates a framework for interviews based on the connotation of food hygiene in order to conduct interviews with the experts (engaged in the industry, government, and education), and analyzes audio records to identify the primary indicators of food safety and hygiene competencies.

This study interviews expert engaged in the foodservice industry, as well as relevant government and education 
employees with more than ten years' experience and an in-depth understanding of employees of the foodservice industry. The numbers of experts of foodservice industry, government, and education are 4, 2, and 3, respectively. The research questions of this study are answered through their narrations of personal experiences and sufficient data.

\subsection{Design of the MDM Questionnaire}

This study uses the Delphi Method, as put forward by Murry and Hammons (1995), replaces the open-ended questionnaire with substantial relevant literature and in-depth interviews with experts, and develops a structural questionnaire to replace the first round survey of the Delphi Method.

This study employs a 3-round MDM questionnaire. Round 1 consists of in-depth interviews and literature review for the development of the structural questionnaire, where the importance of each standard is evaluated by experts (with 5 representing most important and 1 representing least important), and uses open-questions designed to gather experts' suggestions. After the collection, integration, and analysis of each item, the questionnaire is modified to form the questionnaire of the next round. The competences of managers could be classified into three categories, according to the competence model proposed by Schoonover (1998), namely: core competence, management competence, and professional competence. The competence of kitchen staff is classified into core and professional competence.

Regarding the Delphi Method questionnaire; this study found that two or three rounds are best, as experts would reduce their willingness to cooperate for more than three rounds, and two or three rounds of opinions would have stable and consistent results (Walker, 1994). In this study, all the experts reached consensus after three rounds. There were seven personal questions to establish experts' expertise, including name, work company, job position, highest educational level, and work experience in industries related to foodservice or teaching courses.

\subsection{Participant Experts}

Based on the theme of this study, experience, authority, and cooperative willingness are mainly adopted. Regarding the quantity of experts, Delbecq, Andrew, and David (1975) suggested that 15-30 experts should be included in a homogeneous team, while 5-10 should be included in a heterogeneous team. A total of 20 experts of the foodservice industry, government, and academic education were invited to participate. The experts invited by this study have over 10 years of experiences of food safety and hygiene supervision. Among them, three are government hygiene officers with 10-15 years of supervision; five are university teachers of foodservice hygiene courses over 10 years; ten are supervisors or directors of food safety and hygiene departments (including restaurants, independent canteens, chain restaurants, and central kitchens).

\subsection{Data Analysis}

After collecting the MDM questionnaire, the first step is to examine whether or not there are missing items in order to ensure complete and correct data. Regarding the verification of the consistency of experts' opinions, the average mean, standard deviation, and interquartile range are used as assessment criteria. According to the mean averages, the indicators are typed according to their importance (Linstone and Turoff, 2002), where the average mean implies the importance of each indicator. When the average mean is $\geqq 3.5$, it represents that the indicator is considered important by Delphi experts. When the standard deviation is $>1$, it means high numerical discretization and divergence of experts' opinions. The results of the interquartile range of $\leqq 0.5$ implies that the experts reached high consistency in their opinions of the indicators (Fahety, 1979; Wang, Chen, Lee, \& Tsai, 2013). Linstone and Turoff (2002) considered a change of less than $15 \%$ for each item between the two surveys evaluated by all experts indicate stability. The alternative option is total stability, which describes the mean stabilities of all the items equaling or exceeding $70 \%$.

\section{Research Results and Discussion}

\subsection{Comparison of the Results of Three Rounds of MDM Questionnaire}

This model includes three sub- facts for managers, where the most important sub-fact is professional competence, followed by management competence and core competence after three rounds (Table 1). A total of 56 indicators are established in the first round. Regarding the sub-facts of kitchen staff, the ranking of primary indicators in each round is the same: Professional competence outweighs core competence in all three rounds (Table 2). A total of 41 indicators are established in the first round of the questionnaire. 
Table 1. Results of the Sub-Facts of Managers in the Three Rounds of MDM Questionnaire

\begin{tabular}{ccccccc}
\hline \multirow{2}{*}{ Sub-facts } & \multicolumn{2}{c}{ First Round } & \multicolumn{2}{c}{ Second Round } & \multicolumn{2}{c}{ Third Round } \\
\cline { 2 - 7 } & $\begin{array}{c}\text { Average } \\
\text { mean }\end{array}$ & $\begin{array}{c}\text { Interquartile } \\
\text { range }\end{array}$ & $\begin{array}{c}\text { Average } \\
\text { mean }\end{array}$ & $\begin{array}{c}\text { Interquartile } \\
\text { range }\end{array}$ & $\begin{array}{c}\text { Average } \\
\text { mean }\end{array}$ & $\begin{array}{c}\text { Interquartile } \\
\text { range }\end{array}$ \\
\hline Core competence & 4.30 & 0.5 & 4.35 & 0.5 & 4.30 & 0.5 \\
Management competence & 4.50 & 0.5 & 4.55 & 0.5 & 4.80 & 0 \\
Professional competence & 4.85 & 0 & 4.50 & 0.5 & 4.60 & 0.5 \\
\hline
\end{tabular}

Table 2. Results of the Sub-Facts of Kitchen Staff in the Three Rounds of MDM Questionnaire

\begin{tabular}{ccccccc}
\hline \multirow{2}{*}{ Sub-facts } & \multicolumn{2}{c}{ First Round } & \multicolumn{2}{c}{ Second Round } & \multicolumn{2}{c}{ Third Round } \\
\cline { 2 - 7 } & $\begin{array}{c}\text { Average } \\
\text { mean }\end{array}$ & $\begin{array}{c}\text { Interquartile } \\
\text { range }\end{array}$ & $\begin{array}{c}\text { Average } \\
\text { mean }\end{array}$ & $\begin{array}{c}\text { Interquartile } \\
\text { range }\end{array}$ & $\begin{array}{c}\text { Average } \\
\text { mean }\end{array}$ & $\begin{array}{c}\text { Interquartile } \\
\text { range }\end{array}$ \\
\hline Core competence & 4.35 & 0.5 & 4.30 & 0.5 & 4.15 & 0 \\
Professional competence & 4.45 & 0.5 & 4.75 & 0.375 & 4.70 & 0.5 \\
\hline
\end{tabular}

\subsection{Consensus Analysis of Managers' Competences Indicators}

After the three rounds, one indicator was deleted, 23 items were modified or combined, and finally, 47 indicators were constructs. Table 3 summarizes the indicators of managers' competences in the third round of the MDM questionnaire, which shows that, the six average means of "Maintenance, and its application to company certificates", "Understanding the processes of production and marketing", "Understanding the classification of ingredients", "Familiarity with culinary skills", "Diet design", and "R\&D" are all less than 4.00, while those of the remaining indicators are all more than 4.00. Additionally, the interquartile ranges of all indicators are less than or equal to 1 , which fail to reach the criteria to delete an indicator (average mean is less than 4.00; and interquartile range is more than or equal to 1), thus, all indicators are retained in the results of this study.

Table 3. The Experts' Opinions of the Indicators of Managers' Competences in the Third Round of MDM Questionnaire

\begin{tabular}{lllll}
\hline Sub- facets / Indicator & $\begin{array}{l}\text { Average } \\
\text { Mean }\end{array}$ & $\begin{array}{l}\text { Mode } \\
\text { Interquartile } \\
\text { Range }\end{array}$ \\
\hline A-1 & Core competence & 4.30 & 4 & 0.5 \\
\hline A-1-1 & Compliance with norms & 4.75 & 5 & 0 \\
A-1-2 & Professional ethics & 4.85 & 5 & 0 \\
A-1-3 & Communication with consumers & 4.60 & 5 & 0.5 \\
A-1-4 & Elimination of unusual conditions & 4.80 & 5 & 0 \\
A-1-5 & Crisis management & 4.85 & 5 & 0 \\
A-1-6 & Understanding of company policies & 4.70 & 5 & 0.375 \\
A-1-7 & Recognition of corporate culture & 4.30 & 4 & 0.5 \\
A-1-8 & Efficient work & 4.75 & 5 & 0 \\
A-1-9 & Ability to solve problems & 4.70 & 5 & 0.5 \\
A-1-10 & Self-improvement & 4.15 & 4 & 0 \\
A-1-11 & Pursuit of innovation and changes & 4.00 & 4 & 0 \\
A-1-12 & Being calm and prudent & 4.40 & 4 & 0.5 \\
A-1-13 & Good interpersonal relationship & 4.70 & 5 & 0.5 \\
A-1-14 & Organizing ability & 4.70 & 5 & 0.5 \\
A-1-15 & Logical capacity & 4.65 & 5 & 0.5 \\
\hline
\end{tabular}




\begin{tabular}{|c|c|c|c|c|}
\hline \multicolumn{2}{|c|}{ A-2 Management competence } & \multirow{2}{*}{$\begin{array}{l}4.80 \\
4.20\end{array}$} & \multirow{2}{*}{$\frac{5}{4}$} & \multirow{2}{*}{0} \\
\hline A-2-1 & Involvement in teaching and training & & & \\
\hline A-2-2 & Auditing and management ability & 4.35 & 4 & 0.5 \\
\hline A-2-3 & Ability to supervise employees & 4.70 & 5 & 0.5 \\
\hline A-2-4 & Supervision of field work & 4.70 & 5 & 0.5 \\
\hline A-2-5 & Management of employees' hygiene & 4.70 & 5 & 0.375 \\
\hline A-2-6 & Establishment of reward and punishment system & 4.10 & 4 & 0 \\
\hline$A-2-7$ & Providing latest information to employees & 4.15 & 4 & 0 \\
\hline A-2-8 & Performance management & 4.45 & 4 & 0.5 \\
\hline$A-2-9$ & Inspection of suppliers & 4.10 & 4 & 0 \\
\hline A-2-10 & Tasks assigned by the superior & 4.35 & 4 & 0.5 \\
\hline A-2-11 & Maintenance and application of company certificates & 3.95 & 4 & 0 \\
\hline A-2-12 & Leadership & 4.95 & 5 & 0 \\
\hline \multicolumn{2}{|c|}{ A-3 Professional competence } & 4.60 & 5 & .500 \\
\hline A-3-1 & $\begin{array}{l}\text { Understanding of laws and regulations of food safety (e.g. } \\
\text { Food Safety Law, HACCP, GHP, and Food Cloud) }\end{array}$ & 4.85 & 5 & 0 \\
\hline A-3-2 & Familiarity with knowledge of food safety and sanitation & 4.95 & 5 & 0 \\
\hline A-3-3 & Familiarity with national certification and labels & 4.55 & 5 & 0.5 \\
\hline A-3-4 & Understanding of relevant diseases & 4.20 & 4 & 0.375 \\
\hline A-3-5 & $\begin{array}{l}\text { Holding relevant certificates (chef, nutritionist, food } \\
\text { technician) }\end{array}$ & 4.05 & 4 & 0.375 \\
\hline A-3-6 & $\begin{array}{l}\text { Understanding of the measures to prevent and handle food } \\
\text { contamination }\end{array}$ & 4.50 & 5 & 0.5 \\
\hline A-3-7 & Understanding of the processes of production and marketing & 3.95 & 4 & 0 \\
\hline A-3-8 & Establishment of product norms & 4.15 & 4 & 0.375 \\
\hline A-3-9 & $\begin{array}{l}\text { Establishment of processing criteria (environment and } \\
\text { facility, quality control of production workflow, storage, } \\
\text { transport, instrument correction, customer complaint, } \\
\text { product recycling, record, teaching and training) }\end{array}$ & 4.80 & 5 & 0 \\
\hline A-3-10 & Establishment of hygiene SOP & 4.75 & 5 & 0.375 \\
\hline A-3-11 & Familiarity with the procedures of purchase and acceptance & 4.15 & 4 & 0.375 \\
\hline A-3-12 & Understanding the classification of ingredients & 3.95 & 4 & 0 \\
\hline A-3-13 & Familiarity with cooking skills & 3.80 & 4 & 0 \\
\hline A-3-14 & Diet design & 3.75 & 4 & 0.375 \\
\hline A-3-15 & $\mathrm{R} \& \mathrm{D}$ & 3.75 & 4 & 0.5 \\
\hline A-3-16 & Maintenance of workplace security & 4.75 & 5 & 0 \\
\hline A-3-17 & Management of on-site food safety and hygiene & 4.85 & 5 & 0 \\
\hline A-3-18 & Work schedule & 4.75 & 5 & 0.375 \\
\hline A-3-19 & Autonomous management of hygiene & 4.80 & 5 & 0 \\
\hline A-3-20 & Understanding and disclosure of food safety issue (report) & 4.70 & 5 & 0.375 \\
\hline
\end{tabular}

\subsection{Consensus Analysis of Kitchen Staffs' Competences Indicators}

After three rounds of kitchen staff competence, no indicators are deleted, and 20 items are modified or combined, for a total of 35 construct indicators. Table 4 summarizes the experts' opinions of the indicators of kitchen staffs' competences, which shows that, the average mean of "B-1-3 Communicates with customers" is less than 4.00, while those of the remaining indicators are all more than 4.00. Additionally, the interquartile ranges of all indicators are less than or equal to 1 , which fail to reach the criteria to delete an indicator, thus, all indicators are retained in the results of this study. Linstone and Turoff (2002) considered a change of less than $15 \%$ for each item between the two 
surveys evaluated by all experts to indicate stability. The alternative option is total stability, which describes the mean stabilities of all the items equaling or exceeding $70 \%$. The total stability of this study is $90 \%$, indicating high stability and credibility.

Table 4. The Experts' Opinions of the Indicators of Kitchen Staffs' Competences in the Third Round of MDM Questionnaire

\begin{tabular}{|c|c|c|c|c|}
\hline \multicolumn{2}{|c|}{ Sub- facets / Indicator } & \multirow{2}{*}{$\begin{array}{l}\text { Average } \\
\text { Mean }\end{array}$} & \multirow{2}{*}{$\begin{array}{l}\text { Mode } \\
4\end{array}$} & \multirow{2}{*}{$\begin{array}{l}\begin{array}{l}\text { Interquartile } \\
\text { Range }\end{array} \\
0\end{array}$} \\
\hline B-1 & Core competence & & & \\
\hline B-1-1 & Compliance with norms & 4.70 & 5 & 0.375 \\
\hline B-1-2 & Professional ethics & 4.85 & 5 & 0 \\
\hline B-1-3 & Communication with consumers & 3.90 & 4 & 0 \\
\hline B-1-4 & Elimination of unusual conditions & 4.60 & 5 & 0.5 \\
\hline B-1-5 & Crisis management & 4.30 & 4 & 0.5 \\
\hline B-1-6 & Understanding of company policies & 4.05 & 4 & 0 \\
\hline B-1-7 & Recognition of corporate culture & 4.25 & 4 & 0.5 \\
\hline B-1-8 & Autonomous management of hygiene & 4.80 & 5 & 0 \\
\hline B-1-9 & Participation in the seminars of licensed chef on hygiene & 4.75 & 5 & 0.375 \\
\hline B-1-10 & Receiving basic education and training held by a company & 4.80 & 5 & 0 \\
\hline B-1-11 & Self-reflection & 4.65 & 5 & 0.375 \\
\hline B-1-12 & Compliance with dress and appearance & 4.85 & 5 & 0 \\
\hline B-1-13 & Positioning and homing & 4.75 & 5 & 0 \\
\hline B-1-14 & Self-improvement & 4.00 & 4 & 0 \\
\hline B-1-15 & Executive capacity & 4.75 & 5 & 0.375 \\
\hline B-2 & Professional competence & 4.70 & 5 & 0.5 \\
\hline B-2-1 & $\begin{array}{l}\text { Understanding of the laws and regulations of food safety (e.g. } \\
\text { Food Safety Law, HACCP, GHP, and Food Cloud) }\end{array}$ & 4.15 & 4 & 0 \\
\hline B-2-2 & Familiarity with the knowledge of food safety and sanitation & 4.80 & 5 & 0 \\
\hline B-2-3 & Understanding of product tracking and management & 4.10 & 4 & 0 \\
\hline B-2-4 & Compliance with norms & 4.70 & 5 & 0.5 \\
\hline B-2-5 & Understanding of cleaning norms & 4.85 & 5 & 0 \\
\hline B-2-6 & Maintenance of environmental hygiene and safety & 4.90 & 5 & 0 \\
\hline B-2-7 & Understanding the basics and usage of food additives & 4.10 & 4 & 0 \\
\hline B-2-8 & Class III certificates (Chinese cuisine/Western cuisine/bakery) & 4.80 & 5 & 0 \\
\hline B-2-9 & Familiarity of basic cooking procedures & 4.75 & 5 & 0.375 \\
\hline B-2-10 & Maintenance and usage of cooking utensils and equipment & 4.80 & 5 & 0 \\
\hline B-2-11 & Ingredient management & 4.85 & 5 & 0 \\
\hline B-2-12 & Understanding the properties of ingredients & 4.85 & 5 & 0 \\
\hline B-2-13 & Understanding the correct ways of food storage & 4.90 & 5 & 0 \\
\hline B-2-14 & Implementation of ingredient acceptance & 4.80 & 5 & 0 \\
\hline B-2-15 & Correct filling in and submitting forms & 4.55 & 5 & 0.5 \\
\hline B-2-16 & Hand washing and disinfection & 5.00 & 5 & 0 \\
\hline B-2-17 & Compliance with the principle of first-in-first-out (FIFO) & 4.95 & 5 & 0 \\
\hline B-2-18 & Correction application of basic measuring tools & 4.90 & 5 & 0 \\
\hline B-2-19 & Waste classification & 4.75 & 5 & 0.375 \\
\hline B-2-20 & Correct application and management of detergent & 4.95 & 5 & 0 \\
\hline
\end{tabular}


The statistical results show that, the average means of "professional ethics" in the core competences of both managers and kitchen staff are all close to 5 (manager, 4.95; kitchen staff, 4.9), which means that professional ethics is considered an extremely important competence. Enterprises are most concerned about the ethical elements of human behavior, as related to "legitimate" or "illegitimate", what people do, and how their actions affect others (Yeung, 2014). Moral and immoral behaviors may affect individuals, organizations, enterprises, or even entire societies. Rakichevikj, Strezoska, and Najdeska (2010) pointed out that undergraduates attach extremely high importance to the professional ethics and service attitudes of practitioners in tourism and catering industries. Professional ethics could construct corporate culture and enhance enterprise competitive edge.

In terms of professional competence, "understanding the laws and regulations of food safety" and "understanding the knowledge of food safety and sanitation" are considered important competences of managers, while "understanding cleaning norms" and "maintenance of environmental hygiene and safety" are deemed as the primary competences of kitchen staff. Kitchen staff should pay greater attention to hygiene, especially hand washing. In order to keep food fresh and safe, they should comply with the principles of FIFO and make detailed records. In addition, they should understand each step of their workflow, including the application, concentration, and use of detergent. Good food hygiene in the food and catering industry could prevent customers from foodborne illnesses (EU, 2004), thus, practitioners should have sufficient knowledge and skills to meet food hygiene norms, as a lack or negligence of knowledge is an important cause of foodborne illnesses (WHO, 2000).

Regarding managers, in addition to core and professional competences, management competence includes the "ability to solve problems" and "on-site management of food safety and hygiene", and their average means were higher than other indicators. Senior managers should have leadership and professional abilities (Lee, Chang, and Teng, 2008). Leadership and interpersonal skills and communication abilities are the most important and common competencies of a manager. The leadership of a leader is essential to lead and develop an organization (Koenigsfeld, 2012).

\subsection{Comparison of the Indicators of Food Safety and Hygiene of Managers and Kitchen Staff}

Some managers and kitchen staff have duplicate indicators in terms of core competence and professional competence. Comparison of the same competences of different posts, via T-testing of independent samples (Table 5), reveals that, regarding managers' core competence, the scores of "communicate with customers", "elimination of unusual conditions", "crisis management", and "understanding of company policies" are significantly higher than those of kitchen staff. Regarding professional competence, the score of "understanding the laws and regulations of food safety" of managers is significantly higher than that of kitchen staff. Compared with kitchen staff, managers are expected to have better crisis management and communication skills in order to cope with any unpredictable on-site situation. Contrarily, in terms of "holding relevant licenses (chef, nutritionist, and food technician)/Class III certificates", the scores of kitchen staffs are significantly higher than that of managers. In response to the demand for increased requirements for food safety and hygiene at work, managers shall obtain more difficult certificates, such as, certificates of food technician and nutritionist, HACCP, etc.; however, common certificates are vital for kitchen staff. The system to earn a Chinese cuisine chef certificate has prominent significance due to its enhancement of food hygiene (MOHW/FDA, 2016b). Regarding familiarity with laws and regulations, due to the frequent occurrences of food safety issues in recent years, laws and regulations in food safety are often amended. Thus, managers should pay attention to such amendments, make corresponding suggestions and improvement to their workflow, and offer education and training on relevant laws and regulations to kitchen staff.

\section{Conclusion and Suggestions}

\subsection{Conclusion}

The important competences for managers are management competence, professional competence, and core competence (from high to low). The research results of this part have confirmed 47 competence indicators of food safety and sanitation for managers. The average mean of professional competence is high for kitchen staff. The research results of this part have confirmed 35 competence indicators of food safety and sanitation for kitchen staff. Managers' score of understanding the laws and regulations of food safety is significantly higher than that of kitchen staff. In addition, only kitchen staff's average mean of holding relevant licenses/Class III certificates is significantly higher than that of managers. 
Table 5. Differences of the Scores of Same Indicators between Managers and Kitchen Staff

\begin{tabular}{|c|c|c|c|c|c|c|c|}
\hline Indicators & & Job & Number & Mean & S.D. & t Value & Post Hoc Test \\
\hline \multirow{2}{*}{ Compliance with norms } & (1) & Manager & 20 & 4.75 & .550 & .567 & \multirow{2}{*}{ No significant } \\
\hline & (2) & Kitchen staff & 20 & 4.70 & .571 & & \\
\hline \multirow{2}{*}{ Professional ethics } & (1) & Manager & 20 & 4.85 & .489 & - & \multirow{2}{*}{ No significant } \\
\hline & (2) & Kitchen staff & 20 & 4.85 & .489 & & \\
\hline \multirow{2}{*}{ Communication with consumers } & (1) & Manager & 20 & 4.60 & .503 & 4.273 & \multirow{2}{*}{$1>2 * * *$} \\
\hline & (2) & Kitchen staff & 20 & 3.90 & .553 & & \\
\hline \multirow{2}{*}{ Elimination of unusual conditions } & (1) & Manager & 20 & 4.80 & .410 & 2.179 & \multirow{2}{*}{$1>2 *$} \\
\hline & (2) & Kitchen staff & 20 & 4.60 & .503 & & \\
\hline \multirow{2}{*}{ Crisis management } & (1) & Manager & 20 & 4.85 & .366 & 4.819 & \multirow{2}{*}{$1>2 * * *$} \\
\hline & (2) & Kitchen staff & 20 & 4.30 & .470 & & \\
\hline \multirow{2}{*}{ Understanding of company policies } & (1) & Manager & 20 & 4.70 & .571 & 4.951 & \multirow{2}{*}{$1>2 * * *$} \\
\hline & (2) & Kitchen staff & 20 & 4.05 & .510 & & \\
\hline \multirow{2}{*}{ Recognition of corporate culture } & (1) & Manager & 20 & 4.30 & .657 & .326 & \multirow{2}{*}{ No significant } \\
\hline & (2) & Kitchen staff & 20 & 4.25 & .550 & & \\
\hline \multirow{2}{*}{ Self-improvement } & (1) & Manager & 20 & 4.15 & .489 & 1.371 & \multirow{2}{*}{ No significant } \\
\hline & (2) & Kitchen staff & 20 & 4.00 & .649 & & \\
\hline Understanding the laws and & & & 20 & 4.85 & .366 & 5.480 & \\
\hline regulations of food safety (e.g. Food & (1) & Manager & 20 & 4.15 & .366 & & \\
\hline $\begin{array}{l}\text { Safety Law, HACCP, GHP, and Food } \\
\text { Cloud) }\end{array}$ & (2) & Kitchen staff & & & & & $1>2^{* * *}$ \\
\hline \multirow{2}{*}{$\begin{array}{l}\text { Familiarity with the knowledge of } \\
\text { food safety and sanitation }\end{array}$} & (1) & Manager & 20 & 4.95 & .224 & 1.831 & \multirow{2}{*}{ No significant } \\
\hline & (2) & Kitchen staff & 20 & 4.80 & .410 & & \\
\hline \multirow{2}{*}{$\begin{array}{l}\text { Holding relevant certificates (chef, } \\
\text { nutritionist, and food } \\
\text { technician)/Class III certificates } \\
\text { (Chinese cuisine/Western } \\
\text { cuisine/bakery) }\end{array}$} & (1) & Manager & 20 & 4.05 & .686 & -4.265 & \multirow[b]{2}{*}{$2>1 * * *$} \\
\hline & (2) & Kitchen staff & 20 & 4.80 & .410 & & \\
\hline \multirow{2}{*}{$\begin{array}{l}\text { Understanding the processes of } \\
\text { production and } \\
\text { marketing/understanding of product } \\
\text { tracking and management }\end{array}$} & (1) & Manager & 20 & 3.95 & .394 & -1.000 & \multirow[b]{2}{*}{ No significant } \\
\hline & (2) & Kitchen staff & 20 & 4.10 & .553 & & \\
\hline
\end{tabular}

\subsection{Research Suggestions}

6.2.1 Suggestions to Managers in the Foodservice Industry

According to the experts, professional ethics, crisis management, and elimination of unusual conditions are the top three core competences, as all foodservice industry practitioners are expected to have rich experience in the industry, as well as sufficient and basic training of internal and external fields, in order to cope with emergency conditions. The three indicators of management competence are leadership, supervision of field work, and management of employees' hygiene. In addition, managers must manage their workplace hygiene, and control hygiene and safety before, during, and after work, thus, they can enhance their management ability through work experience and further in-service education on leadership. The professional competences include intimate knowledge of food safety and hygiene, understanding the laws and regulations of food safety (e.g. Food Safety Law, HACCP, GHP, and Food Cloud), and on-site management of food safety and hygiene. Managers are expected to learn how to apply the knowledge and regulations of food safety in practice, study relevant courses on GHP, GMP, HACCP, and ISO 22000 according to the requirements of their companies, exchange ideas with the hygiene management staff of other enterprises to facilitate hygiene workflow, and regularly update on-site workflow in order to meet the latest requirements of hygiene and safety. Managers know much more about "understanding the laws and regulations of 
food safety" than kitchen staff, and through education and training opportunities provided by enterprises, they can learn the latest laws and regulations provided on the websites of the Ministry of Health and Welfare in order to improve themselves.

\subsubsection{Suggestions to Kitchen Staff of the Foodservice Industry}

The statistical results of the expert suggestions show that the important indicators of core competence are professional ethics, compliance with dress and appearance, and autonomous management of hygiene. Kitchen staff must always pay attention to the hygiene of their clothes and hands, and comply with the hygiene norms in order to prevent the occurrence of food safety issues.

The three indicators of professional competence are hand washing and disinfection, compliance with the principles of FIFO, and correct application and management of detergent, implying that kitchen staff shall pay attention to the details of their workflow. For instance, without any negligence, they must wash and disinfect their hands before starting to work, which is in line with the standard hand washing procedures. While taking ingredients from a warehouse, pantry, or refrigerator, they shall follow the principles of FIFO and make detailed records. In terms of detergent usage, they shall follow the recommended concentration and cleaning procedures stipulated in the SOP. When kitchen staff become familiar with work details, they will enhance their work efficiency, thus, it is vital for kitchen staff to have basic certificates (Class III). As stipulated by law, the catering industry must have a certain proportion of licensed chefs. Scholars unanimously believe that relevant certificates of the catering industry have influence on improving the knowledge of food service hygiene. Thus, future and current practitioners in the catering industry shall consider relevant certificates as their professional competence.

\subsubsection{Suggestions to Training and Education Courses of Foodservice Industry}

In recent years, Taiwanese and international food safety issues have emerged one after another, thus, laws and regulations on food hygiene and safety have been constantly revised. Owners in the catering industry shall provide sufficient education and training to their employees in order to keep up with the latest information and adjust training content accordingly. As customers pay more attention to food safety and sanitation, in order to succeed, a restaurant must have good food and comply with strict food safety and hygiene norms, as failure to do so may lead to customer dissatisfaction and failure to achieve sustainable operation.

The results of this study imply that no matter whether kitchen staff or managers, their average means of professional competence are higher than those of core competence and management competence. Hence, in catering education, top priority shall be paid to professional competence, laws and regulations, knowledge of food hygiene and safety, and operational procedures, followed by core competence and management competence.

In foodservice education, schools shall train their students' professional abilities through basic courses and conduct simulations of actual workplace via internships. It is suggested that, in the courses of theory and internship, knowledge, operation, and laws and regulations related to catering hygiene and safety should be indirectly introduced, in order that students can become familiar with hygiene procedures in practice, and consider how to actually implement such hygiene procedures in internship courses or even individual habits.

\subsubsection{Suggestions to Future Research}

This study adopted MDM to design the questionnaire, which can be improved in many parts, and future researchers can follow the research direction and conduct further study on the topic or variables. The subjects of this study are all foodservice employees, and are classified according to their job functions into managers and kitchen staff. The latter has not been further classified according to their posts (e.g. internal and external fields). Hence, future researchers can probe into the competencies of food safety and hygiene based on different posts. This study has not conducted follow-up survey on the foodservice employees, and thus, suggests that future researchers can make questionnaires based on each indicator to assess both managers and kitchen staff. The limitation of this study was the questionnaire had been completed by respondents based on their subjective perceptions or opinions, which might be different due to individual factors. As most of the experts participating in this study were managers, they may have subjective opinions regarding some questions due to the influence of their current posts and work content. The experts of different posts had different ideas on the competencies of food safety and hygiene.

\section{References}

Birdir, K., \& Pearson, T. E. (2000). Research chefs' competencies: A Delphi approach. International Journal of Contemporary Hospitality Management, 12(3), 205-209. https://doi.org/10.1108/09596110010309989 
Brannon, L., York, V.K., Robert, K.R., Shanklin, C.W., \& Howells, A.D. (2009). Appreciation of food safety practices based on level of experience. Journal of Foodservice Business Research, 12, 134-154. https://doi.org/10.1080/15378020902910462

Delbecq, A. L., Van de Ven, A.H., \& Gustafason, D.H. (1975). Group techniques for program planning: A guide to nominal group and Delphi processes. Glenview, IL: Scott, Foresman and Company.

Dima F. K., Victor K., \& Ewen T. (2015). Investigating a link of two different types of food business management to the food safety knowledge, attitudes and practices of food handlers in Beirut, Lebanon. Food Control, 55, 166-175. https://doi.org/10.1016/j.foodcont.2015.02.045

EU (European Union) (2004). Corrigendum to Regulation (EC) No 852/2004 of the European Parliament and of the Council of 29 April 2004 on the hygiene of foodstuffs. Official Journal, L226, 3-21.

Fahety, V. (1979). Continuing social work education: Resulte of delphi survey. Journal of Education for Social Work, 15(1), 12-19. https://doi.org/10.1080/00220612.1979.10671539

Fatimah, U.Z.A.U., Strohbehn, C.H., \& Arendt, S.W. (2014). An empirical investigation of food safety culture in onsite foodservice operations. Food Control, 46, 255-263. https://doi.org/10.1016/j.foodcont.2014.05.029

Greig J.D., Todd E.C., Bartleson C.A., \& Michaels B.S. (2007). Outbreaks where food workers have been implicated in the spread of foodborne disease. Part 1. Description of the problem, methods, and agents involved. Journal of Food Protection, 70 (7), 1752-1761. https://doi.org/10.4315/0362-028X-70.7.1752

Hislop, N., \& Shaw, K. (2009). Food safety knowledge retention study. Journal of Food Protection, 72(2), 431-435. https://doi.org/10.4315/0362-028X-72.2.431

Hollden, M.C., \& Wedman, J.F. (1993). Future issues of computer-mediated communication: the results of a Delphi study. Educational Technology, Research and Development, 41(4), 5-24. https://doi.org/10.1007/BF02297509

Horng, J. S., \& Lee, Y. C. (2006). What does it take to be a creative culinary artist? Journal of Culinary Science and Technology, 5(2/3), 5-22.

Howes, M., McEwan, S., Griffiths, M., \& Harris, L. (1996), Food handler certification by home study: measuring changes in knowledge and behavior, Dairy. Food and Environmental Sanitation, 16(11), 737-744.

Kay, C., \& Russette, J. (2000). Hospitality-management competencies. The Cornell Hotel and Restaurant Administration Quarterly, 41(2), 52-63. https://doi.org/10.1177/001088040004100217

Ko, W. H., \& Li, C.C. (2010). The Study on Relationship among Professional Competence, Continuing Education and Career Development for Chinese Chef in Taiwan. Journal of Hospitality and Home Economics, 7, 261-284.

Ko, W.H. (2015). The perceptions and practices of food safety regulations for food suppliers in Taiwan. Journal of Food and Drug Analysis, 23, 778-787. https://doi.org/10.1016/j.jfda.2015.05.006

Ko, W.H., \& Hsiao, C.Y. (2008). To Evaluate the Professional Competence of Chef-Applying in Analysis Hierarchy Process. Journal of Hospitality and Home Economics, 5, 69-91.

Koenigsfeld, J. P., Youn, H., Perdue, J., \& Woods, R. H. (2012). Revised competencies for private clubmanagers. International Journal of Contemporary Hospitality Management, 24(7), 1066-1087. https://doi.org/10.1108/09596111211258928

Lee, L.C., Chang, Y.H., \& Teng, Y.U. (2008). Suitable Jobs, Right Persons: The Personality and Skills for Good Executive Managers of International Tourist Hotels. Annals of Leisure and Recreation Research, 2(2), 19-61.

Linstone, H.A., \& Turoff, M. (2002). The Delphi Method: Techniques and Applications. Addison-Wesley Publishing Company Inc., MA.

Lynch R.A., Elledge B.L., Griffith C.C., \& Boatright D.T. (2003). A comparison of food safety knowledge among restaurant managers, by source of training and experience, in Oklahoma County, Oklahoma. Journal of Environmental Health, 66(2), 9-14.

Mansfield, R. S. (1996). Building Competence Models: Approaches for HR Professionals. Human Resource Management, 35(1),

7-18. https://doi.org/10.1002/(SICI)1099-050X(199621)35:1\%3C7::AID-HRM1\%3E3.0.CO;2-2

McIntyre L., Vallaster L., Wilcott L., Henderson S.B., \& Kosatsky T. (2013). Evaluation of food safety knowledge, attitudes and self-reported hand washing practices in FOODSAFE trained and untrained food handlers in British 
Columbia, Canada. Food Control, 30(1), 150-156. https://doi.org/10.1016/j.foodcont.2012.06.034

Ministry of Health and Welfare/ Food Drug Association (MOHW/FDA). (2016a). Act Governing Food Safety and Sanitation. Retrieved from http://consumer.fda.gov.tw/Law/ Detail.aspx? nodeID $=518 \& l a w i d=292$

Ministry of Health and Welfare/ Food Drug Association (MOHW/FDA). (2016b). The question and answer of the act of food safety and sanitation. Retrieved from http://www.fda.gov.tw/tc/includes/GetFile.ashx?mID=19\&id=28907\&chk=ceb2ff64-cdf3-4602-8bbc-a8198612 6282

Murry, J.W., \& Hammons, J.O. (1995). Delphi: A versatile methodology for conducting qualitative research. The Review of Higher Education, 18(4), 423-436. https://doi.org/10.1353/rhe.1995.0008

Ottenbacher, M., \& Harrington, R. J. (2007). The innovation development process of Michelin- starred chefs. International Journal of Contemporary Hospitality Management, 19(6), 444-460. https://doi.org/10.1108/09596110710775110

Rakichevikj, G., Strezoska, J., \& Najdeska, K. (2010). Professional Ethics - Basic Component of Organizational Culture. Biennial International Congress. Tourism \& Hospitality Management, 1168-1177.

Rodgers, S. (2005). Applied research and educational needs in food service management. International Journal of Contemporary Hospitality Management, 17(4), 302-314. https://doi.org/10.1108/09596110510597570

Rohr, A., Luddecke, K., Drusch, S., Muller, M.J., \& von Alvensleben, R. (2005). Food quality and safety - consumer perception and public health concern. Food Control, 16, 649-655. https://doi.org/10.1016/j.foodcont.2004.06.001

Rothwell, W., \& Lindholm, J. (1999). Competence identification, modeling and assessment in the USA. International Journal of Training and Development, 3(2), 90-105. https://doi.org/10.1111/1468-2419.00069

Sani, N.A., \& Siow, O.N. (2014). Knowledge, attitudes and practices of food handlers on food safety in food service operations at the Universiti Kebangsaan Malaysia. Food Control, 37, 210-217. https://doi.org/10.1016/j.foodcont.2013.09.036

Schoonover, S. (1998). Human Resource Competencies for the Year 2000: The Wake-up Call. Society of Human Resource Management, VA: Alexandria.

Seaman P., \& Eves A. (2008). Food hygiene training in small to medium-sized care settings, International Journal of Environmental Health Research, 18(5), 365-374. https://doi.org/10.1080/09603120802272193

Stone, B. (1997). A system's approach to professional development. Journal of Extension, 35(2), 102-122.

Tzeng, F.L., \& Huang, S.Y. (1995). Study on the job-knowledge of the Chinese cook. Journal of Tourism Studies, 1(3), 77-95.

United States Department of Labor, Employment and Training Administration (2006). Building Blocks for Competence Models. 2016/10/06, Retrieved from: http://www.careeronestop.org/CompetenceModel/Pyramid.aspx

Walker, A.M. (1994). A Delphi study of research priorities in the clinical practice of physiotherapy. Physiotherapy, 80, 205-207. https://doi.org/10.1016/S0031-9406(10)61297-7

Wang, Y.F., Chen, S.P., Lee, Y.C., \& Tsai, C.T. (2013). Developimg green management standards for restaurants: an application of green supply chain management. International Journal of Hospitality Mangement, 34, 263-273. https://doi.org/10.1016/j.ijhm.2013.04.001

Wei, J.H., Lu, H.S., \& Lee, L.C. (2008). A Competence Model Study of Middle Manager for Travel Industry. Journal of Aletheia University Sport Knowledge, 5, 370-383.

World Health Organization (WHO) (2000). Food borne disease-A focus for health education (1st ed.). World Health Organization, Geneva, Switzerland.

Yeung, S. (2014). Examining the need of ethics course in China hospitality industry. Procedia - Social and Behavioral Sciences, 144, 212-217. https://doi.org/10.1016/j.sbspro.2014.07.289 